\title{
Inhibition of hemolysis by antibody against the Porphyromonas gingivalis 130-kDa hemagglutinin domain
}

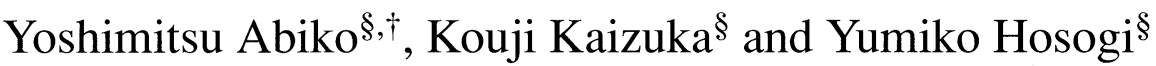 \\ ${ }^{\S}$ Department of Biochemistry and ${ }^{\dagger}$ Research Institute of Oral Science, \\ Nihon University School of Dentistry at Matsudo, Chiba 271-8587
}

(Received 15 February and accepted 18 June 2001)

\begin{abstract}
Porphyromonas gingivalis is a gramnegative anaerobic bacterial species implicated as an important pathogen in the development of adult periodontitis. Hemagglutinin may mediate the adsorption and invasion of bacteria into host cells. Furthermore, the hemagglutinin plays a role in the agglutinate and lyse erythrocytes intake of heme which is an absolute requirement for this bacterial growth. We previously cloned the gene encoding the130-kDa hemagglutinin protein domain (130-kDa HMGD) and identified the functional motifs of agglutination of erythrocytes. Bacterial cell attachment to erythrocytes is an important initial step in the expression of hemolytic activity. In this study, we highly purified recombinant r130-kDa HMGD and prepared the specific antiserum. Further, the effect of the antibody on the hemolytic activity of $P$. gingivalis cells was examined. The polyclonal antibody recognized $43,49-\mathrm{kDa}$ major bands in $P$. gingivalis cells and r130-kDa HMGD, and significantly inhibited the hemagglutinating and hemolytic activities of $\boldsymbol{P}$. gingivalis cells. The findings suggest that the antibody may be useful in the development of the passive immunization against periodontal diseases caused by $\boldsymbol{P}$. gingivalis infection. (J. Oral Sci. 43, 159-163, 2001)
\end{abstract}

Key words: Porphyromonas gingivalis; hemagglutinin; hemolysis; passive immunization.

Correspondence to Dr. Yoshimitsu Abiko, Department of Biochemistry, Nihon University School of Dentistry at Matsudo, 2-870-1, Sakaecho-nishi, Matsudo, Chiba 271-8587, Japan Tel: +81-47-360-9328 Fax: +81-47-360-9329

E-mail address: yabiko@mascat.nihon-u.ac.jp

\section{Introduction}

It is well known that adherence of bacteria to host tissue cells is a prerequisite for colonization and a causative factor in bacterial pathogenesis. The colonization of periodontal pathogens on gingival tissues and agglutination of erythrocytes is critical in the pathogenic process of periodontal disease. Porphyromonas gingivalis, an important pathogen in adult periodontitis, has many potentially virulent factors that have been implicated as participants in the progression of periodontal disease $(1,2)$. It has been reported that $P$. gingivalis has a high adherence activity to erythrocytes and epithelial cells (3). Proteolytic enzymes such as gingipains are known as important virulent factors in pathological events during development and the progression of periodontitis (4). Interestingly these proteases have catalytic domain of protease with hemagglutinin/adhesin domains (4). Further, protoheme, which is derived from erythrocytes in the natural niche of the organism (5), is an absolute requirement for the growth of $P$. gingivalis (6). Additionally, the proteinase-hemagglutinin complexes may have important roles in the uptake of hemin, which is a vital metabolite of $P$. gingivalis, via hemagglutination and the subsequent hemolysis of erythrocytes (7).

Recently, we cloned the gene encoding the $130-\mathrm{kDa}$ hemagglutinin domain (130-kDa HMGD) and identified the functional motifs of hemagglutination. The gene families specifying this motif that are found in the $P$. gingivalis chromosome and encode many hemagglutinin molecules and/or hemagglutinin-related proteases (8). As the development of passive immunization progresses for periodontitis, it should be noted that $P$. gingivalis attachment to erythrocytes is an important initial step in the expression of hemolytic activity. In order to clarify the role of hemagglutinin domains in hemolysis and to develop the passive-immunotherapy, 
we prepared a polyclonal antibody against the purified recombinant 130k-Da HMGD (r130-kDa HMGD) and examined the effect of the specific antibody on hemolytic activity of $P$. gingivalis cells.

\section{Materials and Methods}

\section{Bacterial culture}

P. gingivalis 381 cells were grown in Todd-Hewitt broth (Difco Laboratories, Detroit, MI, USA) supplemented with hemin $(5 \mu \mathrm{g} / \mathrm{ml})$ and vitamin $\mathrm{K}_{1}(5 \mu \mathrm{g} / \mathrm{ml})$ in an anaerobic atmosphere $\left(80 \% \mathrm{~N}_{2}, 10 \% \mathrm{H}_{2}, 10 \% \mathrm{CO}_{2}\right)$ at $37^{\circ} \mathrm{C}$ for 24 to $48 \mathrm{~h}$, and then harvested, washed, and suspended with $\mathrm{NCN}$ buffer ( $3 \mathrm{mM}$ sodium citrate, $0.9 \% \mathrm{NaCl}, \mathrm{pH}$ 6.8). The recombinant Escherichia coli clone, harboring plasmid (pHEM6) coding for the 130-kDa HMGD, was grown on LB (trypton, $1 \%$; yeast extract, $0.5 \% ; \mathrm{NaCl}$, $0.5 \%)$.

\section{Purification of r130-kDa HMGD}

$E$. coli clone cells were harvested by centrifugation $(10,000 \mathrm{~g}, 30 \mathrm{~min})$, washed with $10 \mathrm{mM}$ Tris-HCl buffer (pH 7.4) containing $150 \mathrm{mM} \mathrm{NaCl}$. Since the $\mathrm{r} 130-\mathrm{kDa}$ HMGD protein was highly insoluble, cells were disintegrated by ultrasonication in an ice bath at $1,500 \mathrm{~Hz}$ $(40 \mathrm{~W})$ for 5 cycles ( 5 min sonication and 5 min break) and centrifuged at $30,000 \mathrm{~g}$ for $30 \mathrm{~min}$. The pellet was dissolved with a loading buffer ( $60 \mathrm{mM}$ Tris- $\mathrm{HCl}, 1 \%$ SDS, $7 \%$ glycerol, pH 6.8) and passed through a $0.22 \mu \mathrm{m}$ Millipore filter. The r130-kDa HMGD protein was purified by an electro-osmotic preparative disc SDS-polyacrylamide gel electrophoresis (SDS-PAGE) (9).

\section{Preparation of antibody against $\mathrm{r} 130-\mathrm{kDa}$ HMGD}

Antiserum against r130-kDa HMGD was obtained by immunizing rabbits with an injection of $0.25 \mathrm{mg}$ of the purified r130-kDa HMGD with incomplete Freund's adjuvant, at several sites on the back, once a week for 4 weeks. Three days after the last injection, blood was drawn from an ear vein. Immune serum was passed through a DE52 column (Whatman Ltd, Maidston, Kent, U.K.), then the eluant was applied on a protein $\mathrm{G}$ affinity column (Hitrap affinity column, Pharmacia Biotech, Uppsala, Sweden). The specific antibody was then eluted with $0.2 \mathrm{M}$ glycine$\mathrm{HCl}$ buffer $(\mathrm{pH} 2.3)$ and dialyzed against PBS.

\section{Western blot analyses}

The mini slab SDS-PAGE gel $(7 \times 8 \mathrm{~cm} ; 1.0 \mathrm{~mm}$ thick $)$ was composed of an $8 \%$ separation gel and a $4.5 \%$ tracking gel. Proteins separated by SDS-PAGE were electro- transferred to a nitrocellulose membrane for $1 \mathrm{~h}$ at $6 \mathrm{~V}$ in a transfer buffer (20\% methanol, $50 \mathrm{mM}$ Tris, $40 \mathrm{mM}$ glycine) using a semi-dry transfer cell system (BIO-RAD, Hercules, CA, USA). The nitrocellulose filter was soaked in TBS buffer (10 mM Tris-HCl; $0.15 \mathrm{M} \mathrm{NaCl}, \mathrm{pH} 7.5$ ) containing 5\% low fat milk (TBS-milk) and gently shaken for $30 \mathrm{~min}$. The filter was then incubated with antibody against r130-kDa HMGD (1,000-fold dilution in TBS-milk) for $1 \mathrm{~h}$, followed by peroxidase-conjugated goat antirabbit IgG (1,000-fold dilution in TBS-milk) at room temperature for $60 \mathrm{~min}$. Proteins were detected by incubating the filter with TBS buffer which contained $0.08 \% 3,3$ '-diaminobenzidine tetrahydrochloride and $0.05 \% \mathrm{H}_{2} \mathrm{O}_{2}$.

\section{Assay for hemagglutination and hemolytic activity}

The hemagglutinating activity of the $P$. gingivalis cells was assayed using rabbit erythrocytes in round-bottomed microtiter plates. Fifty $\mu \mathrm{l}$ of $P$. gingivalis cell suspension $\left(2 \times 10^{5} \mathrm{cell} / \mathrm{well}\right)$ was transferred into microtiter wells and incubated with the indicated amount of antibody for 30 min at $37^{\circ} \mathrm{C}$, after which $50 \mu \mathrm{l}$ of $2 \%(\mathrm{v} / \mathrm{v})$ rabbit erythrocytes was added and incubated for $15 \mathrm{~h}$ at $37^{\circ} \mathrm{C}$.

The assay used to measure hemolytic activity was similar to that described by Chu et al. (5) with slight modification. Briefly, $P$. gingivalis cells with and without the incubation of antibody at $37^{\circ} \mathrm{C}$ for $2 \mathrm{~h}$ were mixed with equal volume of $20 \%(\mathrm{v} / \mathrm{v})$ rabbit erythrocytes suspension in sterile microcentrifuge tubes, and $25 \mu \mathrm{l}$ aliquots were immediately removed to establish baseline reading. After which these reaction tubes were incubated at $37^{\circ} \mathrm{C}$. Samples were withdrawn and diluted 10 times with $\mathrm{NCN}$ buffer. The mixture was centrifuged at $1,750 \mathrm{~g}$ for $5 \mathrm{~min}$ to pellet the cellular debris, and the absorption of the supernatant at 415 $\mathrm{nm}$ was measured. Each assay was carried out in triplicatie.

\section{Results}

Western blot analysis showed that antibody against r130-kDa HMGD recognized two major 43 and 49-kDa bands, as well as other smaller bands, but did not recognized the130-kDa band in P. gingivalis cell extracts (Fig. 1 lane 1). The antibody strongly bound to the purified $\mathrm{r} 130-\mathrm{kDa}$ HMGD (Fig. 1 lane 2).

Next we examined the effect of the antibody against r130kDa HMGD on hemagglutinating activity by $P$. gingivalis cells. As shown in Fig. 2, the antibody inhibited the hemagglutinating activity of $P$. gingivalis cells, whereas pre-immune antibody and non-specific rabbit IgG did not.

Finally, we examined the effect of the antibody against 


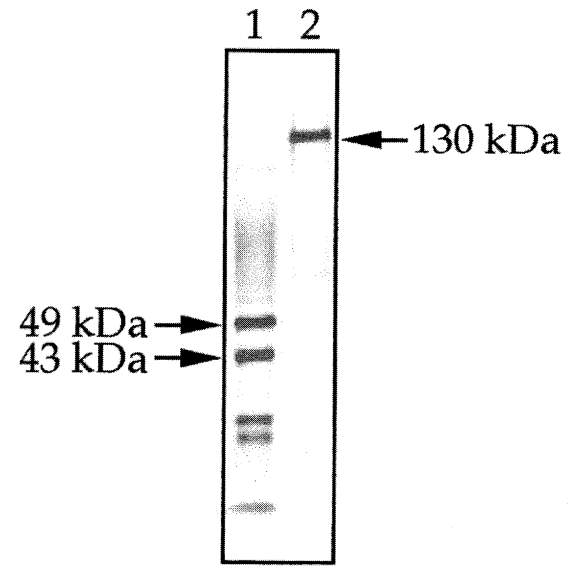

Fig. 1 Western blot analysis of polyclonal antibody against r130-kDa HMGD.

Lane 1, $P$. gingivalis 381 cell extract; Lane 2, purified r130-kDa HMGD.

$P$. gingivalis 381 cells r130-kDa HMGD Ab pre-immune $\mathrm{Ab}$ non-specific $\mathrm{Ab}$ erythrocytes

\begin{tabular}{|c|c|c|c|}
\hline+ & + & + & + \\
\hline- & + & - & - \\
\hline - & - & + & - \\
\hline - & - & - & + \\
\hline+ & + & + & + \\
\hline
\end{tabular}

Fig. 2 Inhibition of $P$. gingivalis haemagglutinating activity by an antibody against r130-kDa HMGD. The hemagglutinating assay is described in Materials and Methods.

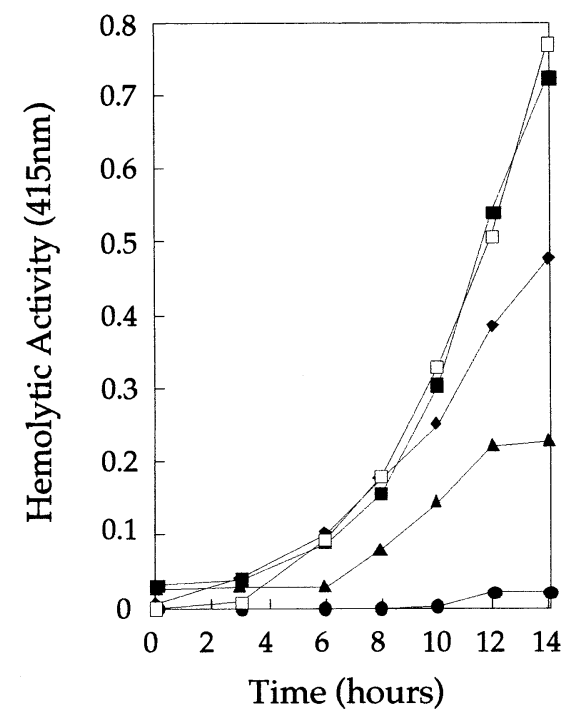

Fig. 3 Effect of polyclonal antibody against r130-kDa HMGD on hemolytic activity of $P$. gingivalis cells. $(12.5$, $\boldsymbol{\Delta} ; 25, \mathbf{O} ; 50 \mu \mathrm{g})$ : Antibody against r130-kDa HMGD. $(\square)$ : non-specific rabbit IgG $(50 \mu \mathrm{g}),(\square)$ : control. All hemolytic assays measured released of hemoglobin and were performed in triplicate.
r130-kDa HMGD on hemolytic activity. The antibody significantly inhibited the hemolytic activity of $P$. gingivalis whole cells both in a dose- and a time-dependent manner. However, non-specific mouse $\operatorname{IgG}$ did not inhibit the activity (Fig 3).

\section{Discussion}

The r130-kDa HMGD was purified as a single band in SDS-PAGE (data not shown) and immunized to rabbits. The antibody obtained recognized the 43 and $49-\mathrm{kDa}$ major bands and not the $130-\mathrm{kDa}$ band in $P$. gingivalis cell extracts and a single band of r130-kDa HMGD. Chandad and Mouton (10) first identified a non-fimbrial and cellbound hemagglutinin (HA-Ag2) associated with $P$. gingivalis, and found that the monospecific polyclonal antiserum against $\mathrm{HA}-\mathrm{Ag} 2$ inhibited hemagglutination. This antibody also recognized the 43 and $49-\mathrm{kDa}$ bands in the outer membrane preparations of $P$. gingivalis cells. Our antibody against r130-kDa HMGD showed similar Western blot profiles as the antibody against HA-Ag2. These findings suggest that $130-\mathrm{kDa}$ HMGD may be the same molecule as HA-Ag2. Further, this 130-kDa hemagglutinin molecule may be processed or modified in $P$. gingivalis cells, and functionally expressed as 43 and 49-kDa bands in $P$. gingivalis cells.

Next, we examined whether the antibody against r130kDa HMGD could inhibit the hemagglutinating activity of whole $P$. gingivalis cells. The results showed that the antibody inhibited the hemagglutinating activity of $P$. gingivalis cells, whereas, pre-immune antiserum and nonspecific IgG did not. The antibody also significantly inhibited the hemolytic activity of $P$. gingivalis cells in a dose-dependent manner.

We performed a homology analysis using the DNA sequence data and found the 14 registered genes (7). Based on the protein structure, these genes included prtK (from the $P$. gingivalis strain, W50), $\operatorname{prtP}(\mathrm{W} 12), \operatorname{kgp}(\mathrm{W} 83,381)$, rgp-1 (H66), prtR (W50), prpR1 (W50), prtH (W83), prtRII (381), rgp2 (H66), rgpB (381), HagD (381), and HagA (381) (7). The complete nucleotide sequencing of DNA fragment encoding 130-kDa HMGD revealed the presence of an insertion sequence similar to insertion sequence (IS) 1126 next to the gene coding for $130 \mathrm{kDa}-$ HMGD (7). Since the IS has the ability to move on a chromosome accompanying a particular gene, it is likely that this IS may help spread the gene coding for the hemagglutinin domain throughout the $P$. gingivalis chromosome. This would contribute to high hemagglutinating activity and cell attachment, and along with the hemolytic activity may transform this bacterium to a more virulent strain. Curtis et al. (11) also pointed out that an 
adherence and antigenic determinant of the Arg-gingipain of $P$. gingivalis is present on multiple gene products.

Since protoheme is an indispensable nutrient of $P$. gingivalis, it seems reasonable to assume that the bacteria lyse erythrocytes through bleeding in the periodontal pocket, thereby degrading hemoglobin and releasing heme. Recently, Nakayama et al. (12) reported that the hemoglobin receptor domain was found in several $P$. gingivalis proteases including Arg-gingipain, Lys-gingipain and hemagglutinin hagA. Furthermore, defects in hemoglobin adsorption and heme accumulation were observed in a Lys-gingipain deficient mutant (13). We found that the hemoglobin receptor domain was located in 130-kDa HMGD (7). This finding is consistent with the concept that, prior to agglutinating erythrocytes through functional motif stretches positioned within the hemoglobin receptor domain, attachment of $P$. gingivalis onto the erythrocyte cell surface may occur. Once the erythrocytes aggregate, then the hemoglobin receptor domain may function under the aid of the protease. This gene structure seems to be ideal in this bacterium for growth in the periodontal pockets and may obtain heme molecules as an iron source.

Passive immunization approaches against oral infectious diseases have been developed (14). Patients with periodontitis, who harbored $P$. gingivalis in their subgingival plaque, were clinically treated to suppress any detectable $P$. gingivalis, and then the monoclonal antibody against $P$. gingivalis cells was applied to their periodontal pockets. Such treatment significantly reduced the recolonization of $P$. gingivalis for up to 9-months (15). When considering passive immunization against periodontal diseases, the pathological focus should be on gingival tissues. Application of a specific antibody that neutralizes bacterial agglutination and hemolytic activity can provide a practical and satisfactory treatment. The antibody presented here may be useful in the development of the passive immunization as well as in the assessment of the treatment of periodontal diseases caused by $P$. gingivalis infection.

\section{Acknowledgments}

A Grant from the Ministry of Education, Culture, Sports, Science, and Technology of Japan to promote 2001Multidisciplinary Research Projects.

\section{References}

1. Slots, J. and Genco, R.J. (1984) Black-pigmented Bacteroides species, Capnocytophaga species, and Actinobacillus actinomycetemcomitans in human periodontal disease: virulence factors in colonization, survival, and tissue destruction. J. Dent. Res. 63, 412-
421

2. Holt, S.C., Kesavalu, L., Walker, S. and Genco, C.A. (1999) Virulence factors of Porphyromonas gingivalis. Periodontol. 2000 20, 168-238

3. Okuda, K., Slots, J and Genco, R.J. (1981) Bacteroides gingivalis, Bacteroides asaccharolyticus, and Bacteroides melaninogenicus subspecies: cell surface morphology and adherence to erythrocytes and human buccal epithelial cells. Curr. Microbiol. $6,7-12$

4. Pike, R., McGraw, W., Potempa, J. and Travis, J. (1994) Lysine- and arginine-specific proteinases from Porphyromonas gingivalis. Isolation, characterization, and evidence for the existence of complexes with hemagglutinins. J. Biol. Chem. $269,406-411$

5. Chu, L., Bramanti, T.E., Ebersole, J.L. and Holt, S.C. (1991) Hemolytic activity in the periodontopathogen Porphyromonas gingivalis: kinetics of enzyme release and localization. Infect. Immun. 59, 19321940

6. Shah, H.N. and Gharbia, S.E. (1989) Lysis of erythrocytes by the secreted cysteine proteinase of Porphyromonas gingivalis W83. FEMS Microbiol. Lett. 52, 213-217

7. Shibata, Y., Hayakawa, M., Takiguchi, H., Shiroza, T. and Abiko, Y. (1999) Determination and characterization of the hemagglutinin-associated short motifs found in Porphyromonas gingivalis multiple gene products. J. Biol. Chem. 274, 50125020

8. Curtis, M.A., Kuramitsu, H.K., Lantz, M., Macrina, F.L., Nakayama, K., Potempa, J., Reynolds, E.C. and Aduse-Opoku, J. (1999) Molecular genetics and nomenclature of proteases of Porphyromonas gingivalis. J. Periodontal Res. 34, 464-472

9. Hayakawa, M., Hosogi, Y., Takiguchi H., Saito, S., Shiroza, T., Shibata, Y., Hiratsuka, K., KiyamaKishikawa, M. and Abiko, Y. (2001) Evaluation of the electroosmotic medium pump system for preparative disk gel electrophoresis. Anal. Biochem. $288,168-175$

10. Chandad, F. and Mouton, C. (1990) Molecular size variation of the hemagglutinating adhesin $\mathrm{HA}-\mathrm{Ag} 2$, a common antigen of Bacteroides gingivalis. Can. J. Microbiol. 36, 690-696

11. Curtis, M.A., Aduse-Opoku, J., Slaney, J.M., Rangarajan, M., Booth, V., Cridland, J. and Shepherd, P. (1996) Characterization of an adherence and antigenic determinant of the ArgI protease of Porphyromonas gingivalis which is present on 
multiple gene products. Infect. Immun. 64, 25322539

12. Nakayama, K., Ratnayake, D.B., Tsukuba, T., Kadowaki, T., Yamamoto, K. and Fujimura, S. (1998) Haemoglobin receptor protein is intragenically encoded by the cysteine proteinaseencoding genes and the haemagglutinin-encoding gene of Porphyromonas gingivalis. Mol. Microbiol. 27, 51-61

13. Okamoto, K., Nakayama, K., Kadowaki, T., Abe, N., Ratnayake, D.B. and Yamamoto, K. (1998) Involvement of a lysine-specific cysteine proteinase in hemoglobin adsorption and heme accumulation by Porphyromonas gingivalis. J. Biol. Chem. 273, 21225-21231

14. Abiko, Y. (2000) Passive Immunization against dental caries and periodontal disease: development of recombinant and human monoclonal antibodies. Crit. Rev. Oral Biol. Med. 11, 140-158

15. Booth, V., Ashley, F.P. and Lehner, T. (1996) Passive immunization with monoclonal antibodies against Porphyromonas gingivalis in patients with periodontitis. Infect. Immun. 64, 422-427 